\title{
Repositioning Research: A New MR Language Model
}

\author{
Virginia Valentine \\ Semiotic Solutions
}

\section{Introduction}

The great MR relaunch debate has raged on for the past decade; in the trade press, at Conference and wherever the role and status of Research crops up. There has been no shortage of suggestions and advice, both from within and without MR. They range from a long-term fundamental strategic overhaul to ditching the Market Research name altogether.

Amongst these recommendations, however, a recurrent theme has emerged; there is something radically wrong with the way that we market ourselves. And, by very definition, that means our communications.

In the light of this, my paper focuses on the MR discourse - the language and imagery that we use to communicate who we are, what we do and how we might contribute, uniquely, to the modern world of strategic planning. Unsurprisingly, I have used semiotics to analyse a broad sweep of MR communications. However, I want to make it clear that this is NOT a paper about semiotics, except insofar as that is the proper research methodology to examine communications. It is a paper about the vital importance of language in repositioning Research — and this is its conclusion.

The MR discourse is based on a set of taken-for-granted assumptions and unconscious cultural beliefs that actually encodes the old imagery of researcher as backroom technician, rather than strategic thinker and boardroom action-maker.

We will not finally shed this image until we break our codes, change our discourse and change our language.

From this argument therefore, I propose a new MR language model that will not only reposition Research to the outside world, but will also challenge the fundamental belief system that lies behind the language we use now.

The model is based on three interactive theoretical premises 
1. The concept of MR as an industry drives our thinking about our future ${ }^{1}$. This is fine as an economic paradigm, but it is the wrong model of thinking for relaunching, repositioning or developing new communications. If, however, we think of MR structurally as a brand we have a substantial and important body of repositioning theory on which we can draw for our relaunch strategy.

2. Semiotics provides a basis for remodelling language as well as for analysing it. My model will therefore include:

- MR codes, how they could be broken, where they should be exploited

- our metaphors, do they or don't they catch the imagination and connect with our client emotions

-a proposed new MR brand myth

3. Market Research inhabits a world of polar opposites. On the one hand, the measurable, quantifiable, systematically collected facts of statistical data. On the other, the inexplicable, intuitive, mad-connection leap into ideas that is the creative world we service. Betwixt these two spaces is a 'liminal zone', a place of transformation, where fact becomes idea; where insight becomes action. From the Greek 'limnos' meaning 'threshold' the liminal zone is an in-between space and time

when what was, is no longer, and what will be, is not yet. It is a place rich with ambiguity, uncertainty and the possibility of creative fomentation ${ }^{\mathrm{i}}$

MR itself is also in a liminal zone, betwixt and between its old image and its new being. It is a place where our identity is up for grabs; where we may be researchers, insight managers, planners, strategicians or creative thinkers - where we switch identity according to the need of the client. It is dangerous, but it is exciting - and it is where, in the view of this paper, the new MR language will be born.

\section{PART 1-Developing A New Language Model}

\section{What are we_-Profession, Industry or Brand?}

The industry urgently needs to redefine itself and explain to the outside world what new market research is all about

(Andy Dexter and David Smith, Research 2001)

Let's start with the notion of redefinition. Who or what are we? The MRS thinks of market research as a profession, we talk about ourselves as an industry and, yes, we are

\footnotetext{
${ }^{1}$ The first session of Conference is entitled The Industry - a Call to Action and includes presentations on repositioning
} 
both of those, but neither provides a model for relaunching ourselves to the outside world.

A profession looks inward to its own ethics and competences, as indeed it must.

Declaring itself to be 'the world's largest professional body for individuals employed in market research', the MRS introduction bounds its existence thus:

To set and enforce the ethical standards to be observed by research practitioners, and to provide a framework of qualifications and membership grades reflecting the education, knowledge and competences required for market research

Fine and important, but not a model for a dynamic — or new—discourse

An industry also looks inward. It is concerned with its own systems and economics. A scan of MR News weekly website in December 2001 produces this collection of items:

1. Upheaval at INRA - again

2. GfK buys into Brazilian agency

3. Microsoft deal on Net respondents

4. Harris cuts staff in US

5. TNS names regional chief

6. Aegis lays out $£ 1 \mathrm{~m}$ for Japanese MR firm

7. GfK grows by $8 \%$ despite problems

8. NFO hires Net expert

9. Pro Active sets up consultancy

10. Direct marketing agency to survey UK businesses

11. Agency goes local

12. Australian election - how opinion shifted

13. WMRC picks FIRM software

The discourse is fixed in the language of company organisation, systems and business economics

In his forthright article on MR's image (Research September 2001) Simon Burrows underlines the problem.

Most pundits only see (the industry) growing. But having reached the level of respectability in the city, most would endorse the need for the business to properly represent itself outside of its own confines.

It is a matter of political history that the Labour party only became electable after 18 wilderness years, when it reinvented itself as the New Labour brand. And it's a matter of research mythology that the party used all the processes and structures of a brand relaunch to achieve its aims. 'On message' actually meant a radical change in language and discourse. From the 'loony' left to the 'sensible' centre ground was as much a linguistic as an ideological shift.

Closer to home, we have the example of advertising. Also an industry-but the image it projects to the outside world is that of the sexy adland brand world. We do, in fact, talk all the time about 'rebranding' market research, but that is to put the cart before the horse. Before we can do the re-branding, we have to go through the transformation 
process to become a brand in the first place. We need, in other words a brand structure to work to.

\section{The MR brand structure}

There are a plethora of well-used structural models for describing, defining and reworking brands. For example:

brand muscle, brand pyramid, brand fingerprint, brand architecture, brand onion..etc

The problem with these tools is, as Mark Earls says, that they are made up of the 'brand-past' ${ }^{\text {,ii }}$. The very vocabulary we have invented for ourselves (pyramid, fingerprint etc) works to underpin this notion of the brand as an unchanging thing. Quite rightly, Earls concludes that this brand-past thinking 'puts a serious psychological brake on invention, tying our thinking to the past (or present)'.

These brand-past models will therefore not do as a basis for relaunching the MR brand. They would only maintain the old language because they cannot think outside the existing discourse.

However, there are models of the brand out there that look to the future and which actually embrace change in their thinking. These tools understand the need to deconstruct the old certainties, and in so doing, leap fearlessly and joyously into the liminal zone. I have taken three of them as a basis for a new MR language model.

\section{Brand Model 1. The Cultural space of consumption}

A company or an industry is, as discussed above, a set of systems: financial systems, manufacturing systems, distributive systems, sales systems - and the MR industry is no different.

At the other end of the spectrum are clients, with their preoccupations and their agendas; their concerns and their politics; their ambitions and their relationships. These are our 'consumers'. Between these polarities there is therefore a brandconsumer relationship. We know that when any consumer looks in the brand mirror, he or she scans the discourse for a reflection of his/her own worldview. This presupposes that brand and consumer inhabit the same culture. The interaction (and buy-in) takes place in 'the cultural space of consumption'.

\section{Industry}

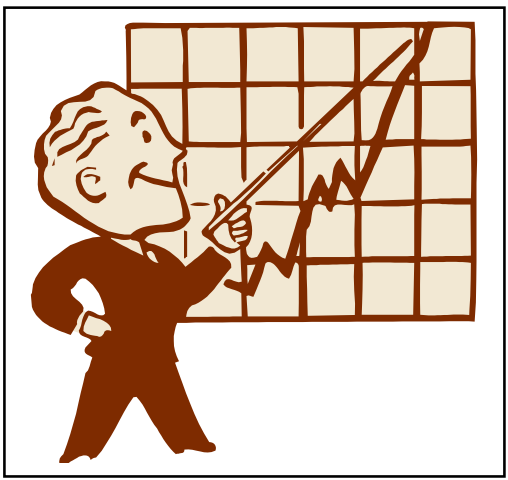

The MR brand
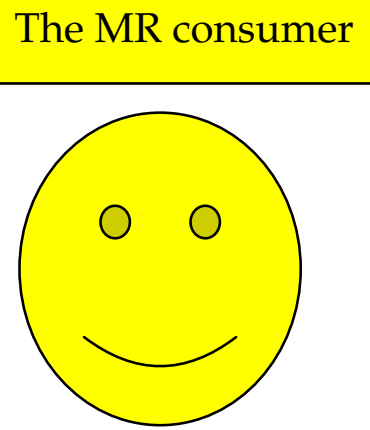

\section{Clients}

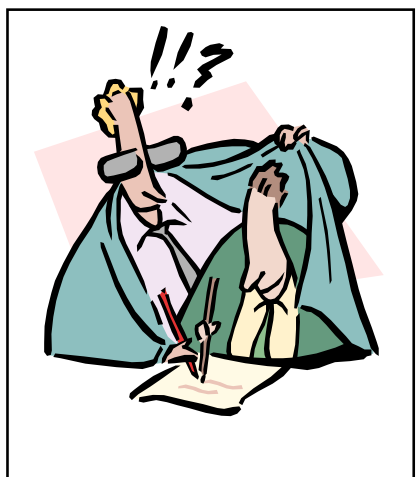




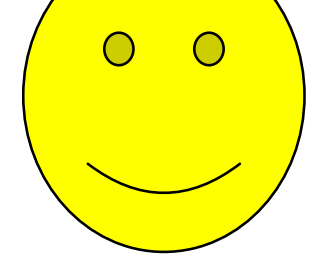

The cultural space of consumption own belief systems, attitudes and cultural values. hically how MR consumers' values have changed. ${ }^{\text {iii }}$

\section{FROM}

Stable and predictable

Large and extensive

Command and control

Control by rules and hierarchy

Information fortress

Rational, quantitative analysis

Need for certainty

Reactive and risk-averse

Process-led endeavour

Consensus

Competing for today's markets

\section{TO}

\author{
Ever changing \\ Quick and responsive \\ Leadership and empowerment \\ Guided by vision and values \\ Information sharing \\ Imagination, creativity and intuition \\ Tolerance of ambiguity \\ Proactive \& entrepreneurial \\ Solution-seeking exploration \\ Constructive contention \\ Creating tomorrow's markets
}

This chimes with the vision of Ian Pearson, BT's futurologist who predicts that as the commercial world moves increasingly into cyberspace, all the client roles we now service will change radically ${ }^{\text {iv }}$

Where today we are aching to get ourselves inside boardrooms peopled with heads of:

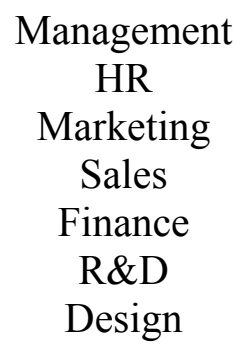

tomorrow's movers and shakers will have job descriptions, maybe even titles, like these

\author{
Creators \\ Assimilators \\ Market-makers \\ Knowledge Guilds \\ Interfacers \\ Facilitators \\ Guides
}

If Pearson is right, and all the consensus analysis of our $21^{\text {st }}$ century world indicates that he is, then this is the emergent code of the MR client and we had better catch up with it. Or, to put it another way, we need to leave behind the residual code of stability and predictability, leapfrog the dominant code of the boardroom that so consistently shuts us out - and be there ready and waiting when the creators, the assimilators and the market-makers turn to look into our brand mirror. 
Come to think of it we already have a place in this new paradigm. What are we if not the 'guides' of the new business world order?

It is significant that Pearson describes this new community of clients as 'Nomadics', arguing that they are not part of the fixed or static manufacturing, packaging, productdelivering side of the company. They may be attached or freelance or simply linked virtually to the static company.

This nomadic space, the space of wandering is a fine example of the liminal zone and it is interesting that the demands of international marketing and world business makes 'Global Nomads' of so many of our clients. This creates a particular kind of consumer personality:

If only as a survival skill, global nomads learn to be adaptable and flexible. It is not uncommon that they develop a measure of confidence in the process of change, and perhaps become so accustomed to change that life without it seems somehow incomplete. (Schaetti and Ramsey, The Global Nomad Experience, Living in Liminality)

From this, the first blocks in the building of a new MR language model emerge

Change, imagination, creativity, intuition, virtuality, ambiguity, a nomadic business and personal existence:

\section{Brand Model 2. The Challenger Brand}

Adam Morgan's concept of the Challenger brand offers an important model of thinking for the MR Language project. Although originally devised to show brands with limited resources how to 'eat the big fish' in their competitive world, the Challenger concept can be applied to any brand or company that wants, in Morgan's words, 'to realise its own potential'. It seems to me that the pain and frustration of MR over the past years has sprung precisely from the feeling that we are not realising our potential. Quotes that describe this are legion, but the Advance Programme for Conference howls the anger and ambition as loud as any.

The papers at Research 2002 will concentrate on the need for researchers to provide the insight and the analysis, and how, by using innovative methodologies and tools, researchers may persuasively communicate the information and relate it to client issues thereby firmly establishing the MR function at the end of the business (their emphasis) The programme aims to demonstrate that MR is an integral part of and not just a supplier for the whole marketing process 
Essentially Morgan argues that Challenger brands need to go through a 4-stage redevelopment - or relaunch. I have reproduced here those elements of each stage that have relevance to a Language Model.

Stage 1: Attitude and Preparation

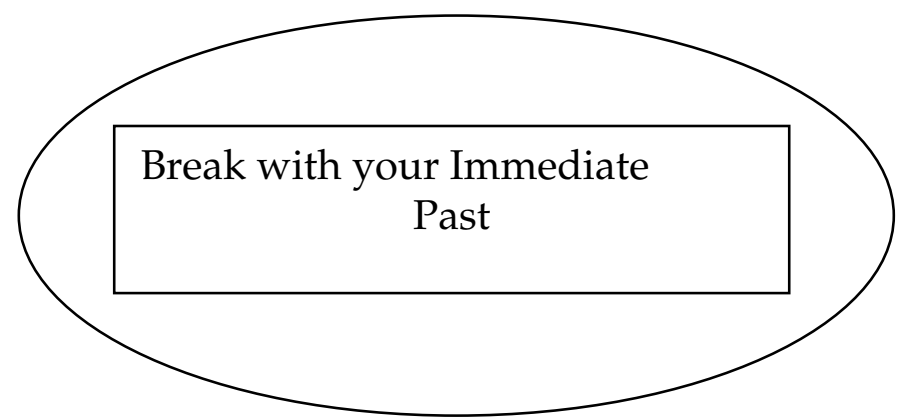

Two points arise from this Stage 1 attitude engineering. Firstly, a break with the immediate past catapults us immediately into a liminal zone.

Victor Turner, whose work on liminality has contributed so much to modern anthropological thought describes going into the liminal zone as the "prophetic break", when seemingly fundamental social principles lose their former efficacy... and new modes of social organisation emerge, ${ }^{\text {v }}$.

Secondly, there is substantial evidence as we shall see below, that MR language currently clings to its past and to its long-established 'seemingly fundamental principles'.

Stage 2: Challenger Strategy

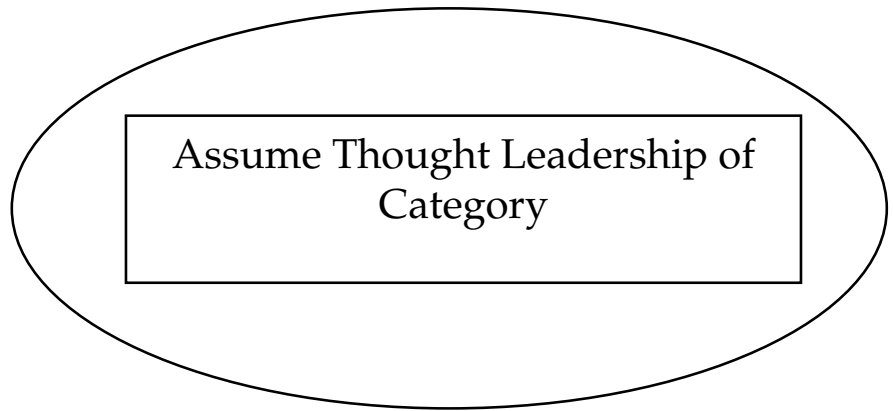

As Morgan has it, Thought Leadership seems to be created ... by breaking one of three kinds of consumer expectation-Conventions of Representation (how you talk about yourself), Medium (where you are) and Experience (what you do beyond talk).

It seems to me that we have, in fact, achieved the third element of Thought Leadership. At our best, what we do is recognised indeed as providing insight to action. The problem lies in the other two elements.

Alongside Thought Leadership, Morgan identifies another tactic in the strategy: to 'create symbols of re-evaluation'. These symbols will 'quickly and emotionally signal to consumers a change in the weather'. 
Stage 3: Challenger Behaviour

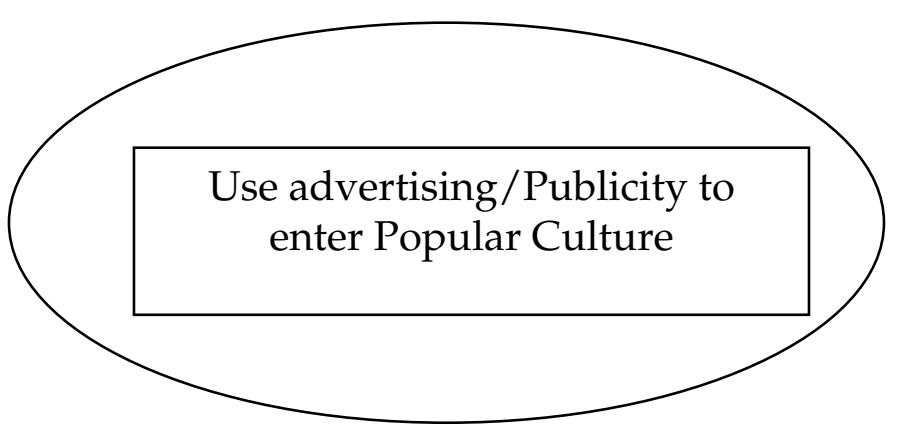

In the Challenger model, 'exceptional and differentiating' advertising ideas are demanded as part of brand behaviour. But as Warwick Cairns points out (Research Dec 2001) 'Someone ought to do some market research into the advertising of the MR industry. They are rubbish and need sorting ou.t'

The semiotic analysis (see Part 2) largely concurs with Cairns' conclusion, but, more importantly, it shows how the advertising is actually counterproductive to achieving the aims of Stages 1 and 2. Far from breaking with the immediate past, MR advertising perpetuates it; and nowhere does it assume thought leadership. And as for creating symbols of re-evaluation: Cairns again 'they are stock shots taken from photo-libraries with a not very funny caption'.

Stage 4: Sustaining Challenger Strategy

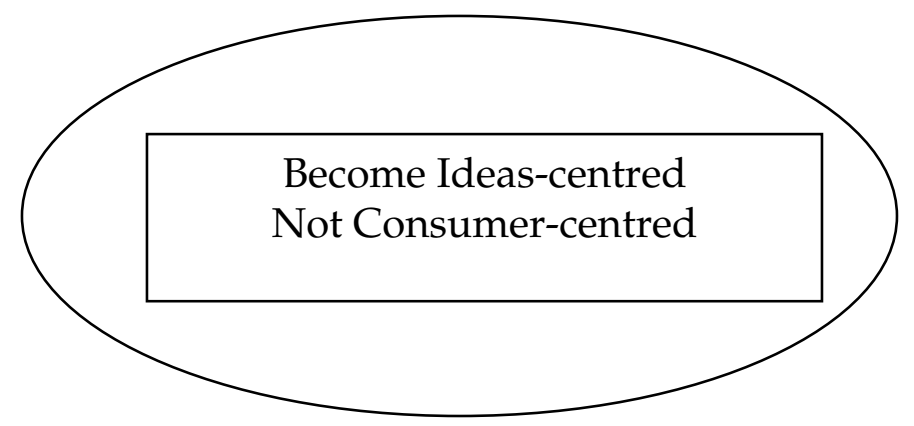

I think it is here that the real advantage of thinking of ourselves as a brand, rather than profession or industry shows itself. Of course what we do is consumer-centred. That is our raison d'être. But, as a brand, relaunching ourselves, Morgan says that we need to give 'primacy to ideas and creative thinking above all else'. Because this is what creates movement and will 'spark new curiosities and perceptions' in the mind of both out clients and the wider world.

The additional benefit of idea-centricity the Challenger Model identifies is worth mentioning here. The spin-off of energy and enthusiasm that 'comes from the sense of possibility and excitement (of) being around stimulating ideas and stimulating people'.

So the elements of our Language Model are building up: 


\section{Change \\ Imagination \\ Creativity \\ Intuition \\ Virtuality, \\ Ambiguity}

Playing to a nomadic business and personal existence

Breaking with the past

Symbolising re-evaluation

Entering popular culture through advertising

Idea-centric

\section{Brand Model 3. Brand as metaphor}

The third brand structure I want to use returns to Mark Earls' paper The Death of Marketing (Conference 2001) Although, as discussed above, the paper might really be said to be anti-brand, or at least anti the way much brand-thinking dominates and misleads marketing and advertising thinking, Earls nonetheless offers important concepts of the-brand-as-structure which are helpful in the context of language.

The concepts include a deconstruction of the brand-as-thing. In Earls' explanation 'the brand is really a set of loose associations in our heads'. But that is exactly how language works. Brand advertising encodes a set of symbolic connotations and associations - based on cultural assumptions and meanings - that are then decoded into an apparently stable idea of the consumer's attitudes to and needs from the product $^{\mathrm{vi}}$

So the brand and language work identically to one another. This bears repeating and stressing. An industry does not work like language. A brand does.

Earls then becomes even more linguistically specific when he writes of the brand as metaphor. In our desire to concretise this loose set of associations and make it into a 'thing' he says 'we forget that the brand is a metaphor to express other stuff'.

But it is as metaphor that brands connect with the imagination and emotional responses of the consumer.

The metaphor superimposes one set of meanings on another, demanding imaginative decoding and, most importantly, the receiver's active participation in making meanings. This is where language plays, slides, goes 'deep' and invokes an emotional dimension when we make the connection in our imagination. ${ }^{\text {vii }}$

Metaphor therefore obeys the Challenger Brand strategy dictat - to 'create symbols of re-evaluation which will...quickly and emotionally signal a change in the weather'. 
Roman Jakobson, the structuralist critic argues that language has two polarities, Metaphor, and its equal and opposite, Metonymy.

Metaphor is at the playful, imaginative end, in which we can include such language forms as mythic discourse, lyric poetry, music, colour and genre. And, of course, advertising and brand properties. Importantly, when we decode metaphors and make their meanings, there is no right answer. We have to feel the meaning. This makes them ambiguous and therefore liminal — and it is this ambiguity, this feeling rather than knowing, that gives metaphor a hotline to the emotions.

Robert Nisbet describes metaphor's liminality thus:

Metaphor is, at its simplest, a way of proceeding from the known to the unknown. It is a way of cognition in which the identifying qualities of one thing are transferred in an instantaneous, almost unconscious flash of insight to some other thing that is, by remoteness or complexity, unknown to us. viii

Metonymic forms of expression, on the other hand, predominate in scientific discourse and in 'clear' or 'transparent' prose generally. And, I'm afraid in the vast bulk of the current MR discourse.

Metonymy is the language of the 'right' answer. To encode or decode metonymically, we must pre-suppose a context. If the Today programme reports that 'Downing Street' said something or other, we do not imagine that the pavement speaks. We put the remark into context and know that because the Prime Minister lives and works at 10 Downing St, the report emanates from his office.

I would want to argue that our desire to be clear, to be unambiguous, to be unfalsifiably 'right' has locked MR into speaking and thinking metonymy; and that this is one of the major reasons we do not engage with the imagination and emotions of either our clients or the outside world. It also has the effect of making all Research appear to be bounded by the data. And, finally, it militates against any form of imaginative makeover.

The new MR Language Model now emerges as:

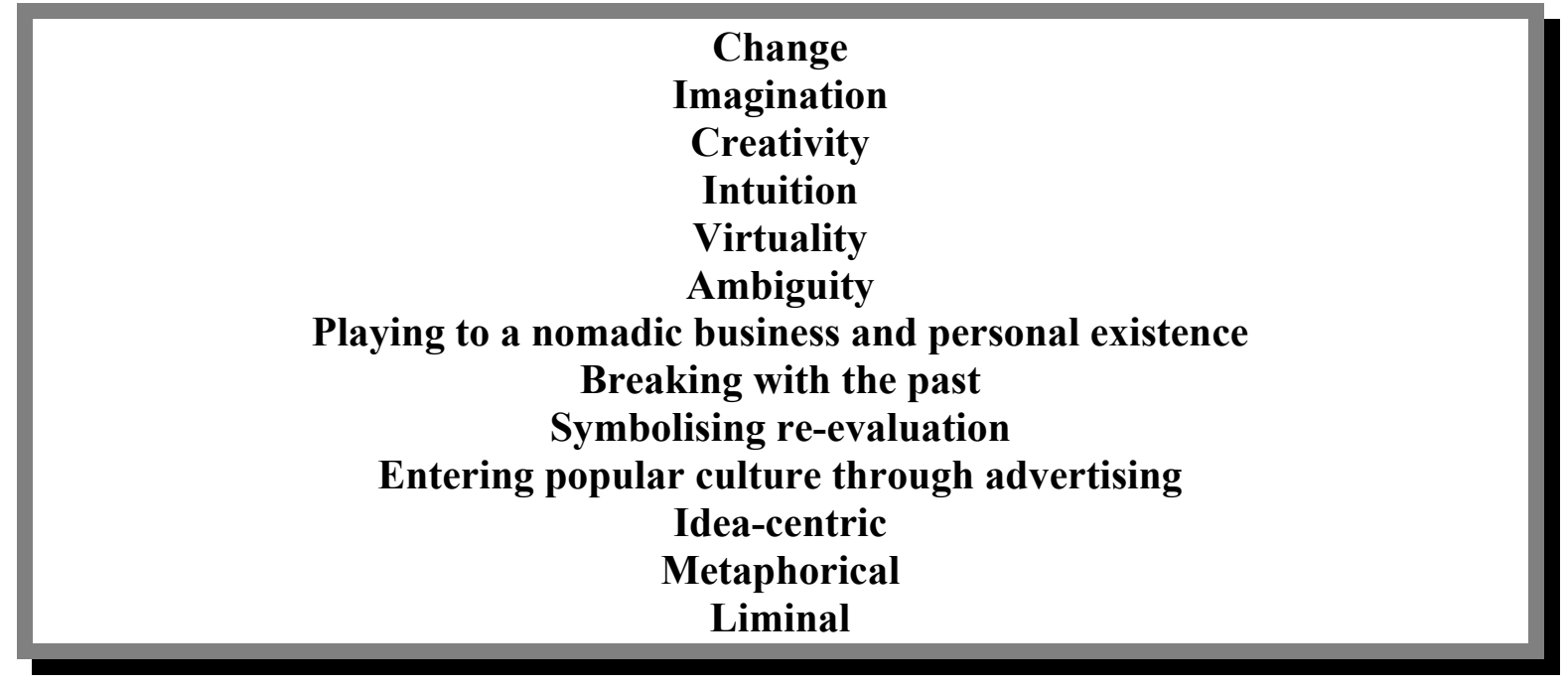


The model forms the basis for the semiotic analysis of the current MR discourse (Part 2 of this paper). However, before leaving this section on brand-structure, I want to make one final point.

\section{What kind of brand are we?}

MR is a diverse beast. Quant is not the same as qual; surveys do not subscribe to anything like the same theoretical and ethical bases as enthography. And as for semiotics... They are all part of what we offer, serving different needs in the process. We have therefore a multi-faceted business, selling often fundamentally different products. And much of our feet-dragging in the matter of relaunching has, I believe, stemmed from the belief that we cannot philosophically (or semiotically) unite them under a single image. But we can if we think retail rather than fmcg.

The Tesco shopper uses household cleaning products in an entirely different way from fine wines; Organics serves a different need to CDs. Yet they are all marketed within the framework of the Tesco brand values and communicated via Tesco's language, imagery and personality. If we think of MR in this way we can transcend the differences and market a philosophy rather than a series of techniques and methods.

\section{The Liminal Zone}

Throughout the paper I have made reference to the Liminal Zone, the place of change, the state of restructuring.

It is therefore apposite that, at the intersection between Part 1, development of the model — and Part 2, the analysis of the MR discourse-I should spend a little time defining this magical space.

\section{Liminality in place and time}

The liminal zone is a place betwixt and between: the beach, between land and sea; the entry to a forest; a cave, suspended above and below ground. And liminal spaces are also thresholds (from which the name derives, interestingly in both Greek, Limnos and Latin, limen) To be at the crossroads is to stand, literally and metaphorically, in a liminal zone.

Crossroads, in liminal theory were 'once considered the most magical of places'. By the same token, crossroads were also dangerous, the burial places of outlaws and witches and the sites of gallows. The Greeks and Romans also worshipped at these intersections.

It is indisputable that MR is at a crossroads. What else is relaunching if not a change from one direction to another. So, willy-nilly we find ourselves here in this place of magic, danger and super-natural power. 
Liminality is temporal as well as spatial. Victor Turner describes the state of liminality as an historical moment when old structures are breaking down to be, eventually, replaced by new structures, which change the course of the culture. It is a time "when the past has lost its grip and the future has not yet put on a definite shape ${ }^{\text {,ix }}$.

In the context of historical change, Turner also provides the blueprint for the liminal zone as a new language crucible.

In long-established cultural systems I would expect to find the growth of symbolic and iconographic syntax and logic. In changing or newly established systems I would expect to find, in liminal situations, daring and innovation, both in the modes of relating symbolic and mythic elements and in the choice of elements to be related. There might also be the introduction of new elements and their various combination with old ones. (Dramas, Fields and Metaphors, Symbolic Action in Human Society)

\section{PART 2}

\section{The current MR discourse: a semiotic overview ${ }^{2}$}

This section of the paper looks at the MR discourse in some depth. Time and length preclude close reading of all our languages in all of our manifestations, but I have taken a broad sweep of MR communications, including:

- the MRS literature and communications

- Research Show

- Research Agency brochures

- Advertisements

- Websites

- Entries in Research Buyers Guide

- Other organisations, eg AQR

And by way of contextual comparison:

- Brand Development Consultancies

- Futurologists

My aim was to map the MR discourse against Turner's definitions of the languages of long-established or changing cultural systems, and against my own new Language Model.

\footnotetext{
${ }^{2}$ Semiotics gives us the language to talk about languages and the way they work and the tools to remake language so that it communicates more effectively.
} 


\section{Two paradigms of communications}

It is a central tenet of semiotic theory that we understand our world through a series of binary oppositions. At Semiotic Solutions, we call this 'the theory of notness'. For example, clean is 'not dirty'; full up is 'not hungry' good is 'not evil'...etc.

We acquire these oppositions as we acquire language...MAMAMA...DADADA ..etc What we actually do is define reality in terms of oppositions. Land/sea; earth/sky and so on. However the key point here is that usually only one part of the opposition is present in our conscious minds; the other is 'absent', present only in the unconscious.

So the language model posited on the left hand side will also have, on the right, its notness, its unconscious oppositions:

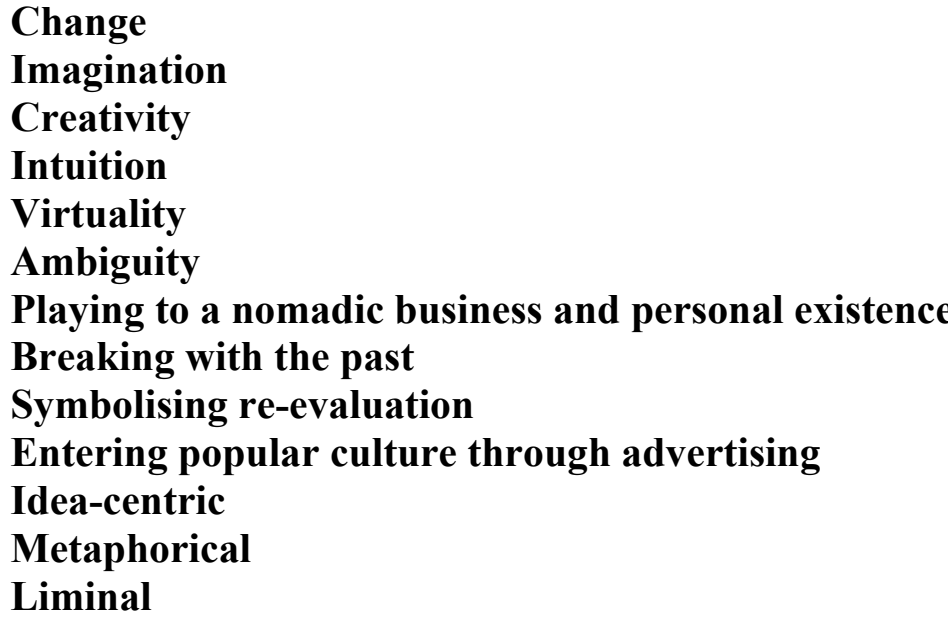

Stability
Knowledge
Information
Evidence
Reality
Certainty
Staying put
Revering past
Complacency
Internal culture
Fact-centric
Metonymic
Structure

Although it comes as no real surprise, it is nonetheless shocking to see, prima facie, that MR is semiotically located firmly on the oppositional side to the new language model.

To investigate this and to find out if the prima facie case was more than mere prejudice, I did some deeper analysis. For the sake of clarity and the constraints of time and space, I first reduced the paradigms to big clusters of oppositions (the clusters are defined by the italics and the other elements are covered within them)

Imagination

Creativity, Intuition

Virtuality

Change

Nomadic existence

Breaking with the past

Symbolising re-evaluation

Idea-centric

Ambiguity

Entering popular culture through advertising

Metaphorical

Liminal
Knowledge

Information, Evidence

Reality

Stability

Staying put

Revering past

Complacency

Fact-centric

Certainty

Internal culture

Metonymic

Structured space

So my final analysis framework looks like this: 
Imagination

Change

Idea-centric

Ambiguity

Popular Culture

Metaphorical

Liminal
Knowledge

Stability

Fact-centric

Certainty

Internal Culture

Metonymic

Structured space

\section{The MR discourse}

\section{The codes of knowledge}

Signifiers of Knowledge are the dominant code in the MR discourse, subsuming within them the codes of Information, Evidence, Reality and Fact-Centricity. Indeed we actually use some of these words in our job specifications. There has even been discussion that we should rename the Market Research function as Knowledge Management.

We offer clients 'findings' or feedback. The dictionary definition of datum is 'thing known or granted'. And, simply from a semiotic rather than a practitioner's point of view the entire quantitative discourse encodes 'knowledge' and 'information'. Science is of course the prime cultural symbol of knowledge and the MR discourse abounds with scientific imagery: not merely in the charts, graphs and diagrams of our debriefs, but in the symbols of agency logos.

It is also interesting to note how many Research Agency names connote 'knowledge'; here is just a random selection: MAP, IPSOS, COGNITION, 20/20, ABACUS, DIAGNOSTICS, FEEDBACK, INFORMER, BIG PICTURE, INFOSEEK, MARKETING SCIENCES, SCIENTIFIC SERVICE and RELEVANT KNOWLEDGE

The actual signifier 'knowledge' and its semantic sisters, 'knowing' and knowledgeable' are familiar in research agency advertising headlines. Ads also use headlines such as 'start well up the learning curve', the end of which journey, of course, is 'knowledge' The problem I would suggest with this is that our clients don't want to stop at knowledge. They want to know what to do with this information when they get it. But this dominant code doesn't signify that deliverable.

The dissected and analysed head is also a familiar image throughout our iconography as is the brain. This is imagery of entering people's heads and 'knowing' what goes on inside them but it also has a secondary reference system of power relations. We, as researchers, construct ourselves as having power over the market consumer. This in turn looks inwards to our own techniques; how we elicit the knowledge rather than the insights we gain.

We do not, by contrast, exhibit any semiotic signs of having power over our own consumers - our clients. Indeed we hardly ever mention our consumers. You can count on the fingers of one hand how often agency publicity uses the shifter 'you' or 'your' to point the client-reader towards his/her own needstates. 
The dominant signifier in MR publicity is 'we'. We deliver, we believe, we offer, we provide. ${ }^{3}$ Contrast this with brand advertising. Just picking up one Sunday supplement at random yielded this crop of 'you'-orientated headlines:

You make it happen; Who do you know who'd love a book token; Indulge the one you love; Whatever turns you on; Want to hear clearly. Throw away your hearing aid; Karina T changes to suit her mood; What do you cook on; Get yourself a new shaver, but don't ever bother to clean it.

And the implicit 'you'-Two's company, three's a crowd, four's a party

No matter the different product discourses that are being tapped here, it is the structure that is important. If we return to the diagram of the cultural space of consumption, we can see that our knowledge-coded, we-centred discourse is in fact constructing an image of our clients as part of the research fraternity. Not marketers or CEOs and certainly not creators, assimilators or market-makers. It's an incestuous research dialogue.

And, as Wendy Gordon has it, codes of knowledge presuppose a right answer when, in fact, 'clients should be encouraging researchers to present possibilities and researchers should have the courage to stand up and say they do not know the answer, but here are a few'. Gordon goes on to posit that 'This ...leads to shared analysis...not one-way presentations of 'findings' or 'data' (and) to more use of the imagination and intuition. ${ }^{\mathrm{x}}$ Arguably, presenting possibilities also takes us into the liminal zone between research and creativity.

\section{The Codes of stability}

Semiotically we stabilise the discourse in several ways.

Linguistically we keep things the same by the unchanging use of familiar methodological terms in methods of data collection: quant, qual, omnibus, U\&A, CATI, CAPI, Tracking Study etc. In this sense that we once again include researchers and exclude everybody who does not live and breathe conjoint analysis or projective techniques.

The discourse does change when it comes to branded products. Here companies conceptualise services in much more client-friendly language. Leapfrog's The Cutting Room stimulus shop; Millward Brown's Dynamic series-SalesDynamics, BrandDynamics etc; TRBI's $360^{\circ}$, Vision or Talking Shop. These are all ways of linguistically reframing services out of methodology and into benefit. But they are agency-specific, the MR brand as a whole sticks rigidly to its prescribed services and methods of data collection, set by the discourse of the profession.

The whole MRS semiotics is interesting here in its stability tactics. Using lines and rules to contain and control typography keeps everything in place as do square blocks of copy. On the codes and guidelines series surrealist imagery which threatens to destabilise our view of what we do (looking, listening, talking) is firmly reined in by a boxed outline.

\footnotetext{
${ }^{3}$ It must be said that Semiotic Solutions also works to this 'we'-centred discourse
} 
The dark blue of the logo is a symbol of authority and establishment and gold is a metasymbol of eternity, authority and enduring values. And the current introduction of purple connotes royalty and establishment and that most unchanging of states - death. Purple is also interestingly the colour most used in pharmaceutical advertising for drugs treating either depression or illnesses that cause psychological problems.

From this several issues arise.

- To semiotically ensure stability is to resist change and that leads to complacency.

O It may be that much of the work that the MRS does is in fact about stabilisation, monitoring professional standards, creating qualification schemes and, above all, setting and protecting ethical standards. But that is not all the society does. Areas such as training, events, special interest and the fostering of new ideas are much more to do with change and creativity and could be given a quite different kind of communications treatment

- The MRS positions itself firmly as the professional anchor for anyone involved in or with an interest in market research. That is genuinely good to know: probably we need to be able to drop anchor every now and then. But, in the interests of developing this industry and this profession, we also need to sail into unchartered waters, be brave, take risks, come at the whole thing from somewhere else. And never so much as now, but the hidden agenda projected by the semiotics do not encourage us to do this.

\section{Metonymy}

If 'knowledge' is the dominant code then metonymy is its semiotic mechanism. To recap: metonymy is the opposite language axis to metaphor. We cannot properly talk about language without understanding metaphor and metonymy any more than we can talk about establishing location without using latitude and longitude.

Where metaphor opens up the meanings, metonymy closes them down. Metaphor allows your imagination to 'feel' the analogy between two terms. Metonymy demands a decoding that provides a 'right' answer. Metaphorically the glass is half full or half empty. Metonymically the glass holds $500 \mathrm{ml}$.

Metonymy is everywhere in the MR discourse. From the charts through which we present our findings to the quasi-scientific language of our reports, we close down the meanings.

Providing the right answer also comes from one component being able to signify a whole context of things, either next to it or logically connected with it: (head for cattle, hands for workers, Downing Street for the UK government, England for the national football team etc).

Amongst MR visual imagery we found several favourite metonymic signifiers. They included countless tired globes or aerial shots of islands or mountains and maps as signifiers of international research capacity. 
Contrast this with NOP's refreshing and sharp use of metonymy in one ad that showed a tribeswoman in highly exotic and authentic dress under the headline 'How Many People In Tahoua have mobile phones?'

Then there are bits of people (lips, eyes, ears) or isotype figures standing in for the whole consumer. And the astonishingly uninventive iconic signifiers of telephones or computers or interviewers metonymically representing, yes you've guessed it, telephone research and field interviews.

Metonymy in the sense of logical connection predominates in agency names. Tens of names have the word 'research' in them; a great many, including our own, make logical connections with 'solutions'. There is a generous spattering of names with the words 'behaviour', attitude', 'consumer', 'insight' and still others connecting via the metonymic signifier 'business'.

Conference's programme semiotics is also highly metonymic. On the cover, the ubiquitous globe, plus technological iconography, silhouetted business travellers and a 'delegate' on a mobile phone. Inside a repeat of the same pictures (ergo the event yields no surprises) and a shot of the exhibition. Nightlife and Fringe visual imagery fares little better, although here the metonymy verges on the absurd with stock shots of deckchairs on the Brighton pebbles standing in for conference fun and entertainment. Even on the website with all the possibilities that offers of creating new imagery and selves for the browser, the Conference Homepage turns up the couple with the suitcases and the mobile phoner.

There are several important dangers in the MR reliance on metonymy. Firstly, it is the semiotic voice (to borrow David Smith's concept) of the old paradigm of technical expertise, knowledge and anti-creativity ${ }^{\mathrm{xi}}$. Secondly, it flies in the face of Sally FordHutchinson's cry for people to become 'passionate' about how they interpret data ${ }^{\mathrm{xii}}$. Metonymy is distanced, objective, and right - passion is close, subjective and takes the risk of being wrong. As Ford-Hutchinson says 'Those who do (become passionate) will be very successful, those who don't will return to the backroom and data processing'.

Thirdly, and perhaps most important of all, because metonymy closes down the options into one meaning, it boxes the reader into one position.

If you can only see one right answer, you cannot see all the other possibilities that are out there. This surely is to reduce the MR contribution to the only thing you think you can be sure of - numbers.

\section{Tired, flat metaphors}

It would be wrong to say that the MR discourse features all metonymy and no metaphor at all. There are, in fact, quite a lot of metaphorical images. A few are exciting and inventive and use all the semiotic possibility of the figure of speech, but so many are tired clichés with no energy. This is ironically particularly true of advertising, where the conventions and the genre itself could open up far more opportunities for creative metaphorical thinking. 
Well-worn cliché'd metaphors include: citrus fruits or mouldy food to signify the need for 'refreshing' and unstale thinking; the inevitable lightbulb for that Eureka moment; ostriches emerging from the sand; several images contrasting mass-produced goods cars, supermarket own brand - with custom-tailored solutions; detergents standing in for 'brilliant' results; stars as signifiers of success...etc...etc.

The semiotic problem here is threefold. Firstly, metaphor works by connecting with the imagination, by setting in train a process of active meaning-making between reader/viewer and text. To requote Robert Nesbit's definition

Metaphor is, at its simplest, a way of proceeding from the known to the unknown. It is a way of cognition in which the identifying qualities of one thing are transferred in an instantaneous, almost unconscious flash of insight to some other thing that is, by remoteness or complexity unknown to us.

If the metaphor is tired, the process lacks the thrilling unconscious moment of the 'flash of insight': the moment when we 'get it'. This has the semiotic effect of diminishing or even negating the workings of the trope. In other words it doesn't 'feel' like a metaphor. If it doesn't feel like a metaphor, it doesn't ring true, and if it doesn't ring true it subverts, or could destroy, the credibility of the point it is trying to make.

Secondly, when a metaphor is used unthinkingly or unimaginatively in this way, it casts a question mark over the addresser's ability to think or behave intuitively or to open up his/her mind to the insights that lie within the data.

And finally, returning to Adam Morgan's Challenger Behaviour and the instruction to 'use advertising to enter popular culture', we, as researchers, know how advertisingliterate the market consumer is and how dismissive s/he is of dull, uninventive advertising. As Malcolm Evans and Michael Harvey say 'Younger consumers are already experts in instinctive semiotics, interacting with advertising and continually upping the stakes of innovations, subtlety, irony and cross-reference' ${ }^{\text {xiii }}$ Advertising today can only get into popular culture if it uses either metaphor (or metonymy) brilliantly.

In her remarkable paper drawing together new neuro-psychological thinking about how brands work in our brains, Wendy Gordon makes the point that 'brand associations are strengthened over time through repetition. ...We are like elephants - we never ever forget-Certain associations are indelible. Think of the Dulux dog or the Andrex puppy ${ }^{\text {xiv }}$

What we 'never forget' is the gorgeous process of making the meaning. Cheat us of that and we will not only forget your metaphor, we'll forget you. 


\section{No- Discourse Logos}

In his book, Marketing and Communication : Beneath the Signs, the Strategies, JeanMarie Floch devotes a chapter to a semiotic analysis of the Apple logo

Our logo is a great mystery: it is a symbol of pleasure and knowledge, partly eaten away and displaying the colours of the rainbow, but not in the proper order. We couldn't wish for a more fitting logo: pleasure, knowledge, hope and anarchy Jean-Louis Gassée, ex-Chairman, Apple Products

Floch enlarges on Gassée's quote: the biblical references to Eve (pleasure and knowledge) and the end of The Flood (the rainbow); the anarchy of the rainbow colour stripes connoting both rebellion and an imaginative mathematics. He also makes the association with The Big Apple and all the connotations of New York. (That, of course, will have changed in the year since his book was published; now the pleasure and the hope are tinged with sadness, deepened by the associations of the WTC with modern technology). And, although Floch doesn't mention it, there's the story that Steve Jobs is doffing a metonymic cap to Alan Turing, the founder of computer science, who died from eating a cyanide-poisoned apple.

The point at issue here is that the more discourses a logo can tap into the more richness it connotes and the more memorable it is. And of course we take the risk that some of the associations might be ambivalent or even antipathetic. But that is the character, and the power, of metaphor.

In comparison, the majority of research agency logos present a much thinner semiotic picture.

They are largely metonymic. Either as acronyms, referring only to the precise words from whose initials they are formed, in which case, there is no discourse at all or pointing inwards towards the discourse of the research industry itself, such as TRBI's TAT thought bubble.

Interestingly, where metaphor is used, it is mainly through scientific and digital signifiers, tapping into the discourse of objective distanced knowledge, rather than the mythic cultural knowledge symbolism of something like an apple.

From this we can see that the greater part of the MR discourse hunkers down and retreats constantly back into its own established thinking. Codes of knowledge, serviced by metonymy predominate. We close down meanings, searching semiotically to project a single 'right' answer - and we turn away from imagination, creativity and passion.

Contrast this with the language and imagery of the brand development consultancies, who are using emergent codes that are working to a new and different set of belief systems. 


\section{Emergent Codes 1. Liminal names}

Liminal thinking is evident in many of the new consultancy names.

The Fourth Room is absolutely defined by its liminality. The name derives from the fable of the Four Rooms where the eponymous Fourth is the Room of Great Unknowing. The slogan 'leap before you look' is an invitation to fling yourself into liminality and the great unknown.

Circus too comes from a liminal place, where people fly and walk in the air. Housed in a non-house, often encamped at crossroads, a marker of festive times and an arch signifier of the topsy-turvy world of carnival, where clowns rule and magical tricks are performed.

Dragon connotes the mythic guardians of the treasure to be found on the other side of the liminal space: the riches, the love of the Princess or - in our case — the insights. Through the Loop linguistically enacts the process of the journey into unknown territory, where the paths are not clear when you start out, but where possible directions appear along the way. Its research company is named in the same coding mould Purple Doors.

What If is a conceptual liminality. In asking the question the name immediately deconstructs past thinking, looking to the future. This is semiotically underpinned by putting the question mark at the beginning rather than the end of the logo. What If describes itself as 'an inventing company' (idea-centricity) and the language majors strongly on creativity. And arguably Identica connotes the finding of the self, a new identity as we cross over the threshold of change.

The brand consultancies do not, however, have a prerogative on liminal names. In the MR world Leapfrog, Mosquito, Flamingo are all evoking the entering or occupation of liminal zones at the water's edge. And Egg is of course the space between conception and birth. (Advertising's Mother is working to the same code.) Informer, whilst still using knowledge in its name, nonetheless positions itself in the liminal world of 'adventures in contemporary culture'

In all of these names there are associations of change and movement of taking risks and of finding your way through the use of art, creativity, imagination and intuition.

Knowledge is just something to help you through the process, not the dominant coding system.

And many of them are also metaphorical, as indeed are other research agency names such as Firefish, $2 \mathrm{cv}$ and Purple Doors.

Of course, not all the brand consultancies use liminality or metaphor in their naming strategies. Interbrand, New Solutions, Added Value, Future Brand etc are still metonymically connected with the old space and structures. But the emergent code is certainly moving that way. 


\section{The language of feelings}

Although the MR brand model I developed in Part 1 of this paper framed most of the semiotic analysis, one new and surprising use of language came out. The consultancies write (and obviously think) in what I can only describe as the language of feelings.

What If's 5 values are listed as Passion, Freshness, Action, Bravery, Love and their people are described as the Inventing team and the Revolution team. Not a 'knowledge' signifier in sight. However, if all this seems a far cry from MR it is salutary to remember that What If's Helen Traviskis won the Best Newcomer at Conference 2000 and a dual client/supplier paper — Seeing is Believing — was presented by their TV company and Unilever last year. It is also instructive that Traviskis's Conference Presentation is not described on What If's website as a (distanced) academic 'paper', but as a (much warmer and more human) 'speech' .

Circus calls itself the 'Brand Engagement' company, a term of closeness and involvement. Baston Greenhill Andrews publishes an annual 'thought and discussion' booklet called Ignite (the metaphorical firing-point of passion). Dragon has created the suggestive and creative acronym D.R.E.A.M for what is, in fact, a down-to-earth, practical brand development tool. FutureBrand urges us to 'embrace the future'.(and much of its corporate brochure imagery is located on the liminal zone of the beach)

New Solutions offers a Soho 'Inspiration Tour' and as the cursor moves over the Home Page it is followed by a Tinkerbell-style magical light. This playful narrative tactic may be a flight of my semiotic fancy (although the connotations are there for anyone who wishes to make them) but Circus talk overtly about telling the brand story in their description of their work. Storytelling is also part of the What If process. And the Fourth Room fable informs the company's whole approach.

\section{Hanging Loose}

Scanning the entries in the Research Buyers Guide one is struck by the number of companies, our own included, who foreground their 'specialisation'-again this is part of the prescribed professional presentation framework, but it also occurs over and over in body copy. Sometimes, like ourselves, focusing on either a methodology or a product area, but more often than not 'specialising' in just being a jolly good research agency. Stuffed, no doubt, with jolly good researchers.

Equally, many of the consultancies are quite specific in their declarations that they are a 'strategic marketing consultancy' or a 'branding consultancy'. These companies are peopled with 'expert marketing and strategic planners'.

However, a new code of company descriptors is emerging:

What If calls itself an 'inventing company' made up of an Inventing Team, a Revolution Team and an Impact Team; The Fourth Room is a 'team of senior creative strategists. 
working collegiately'; Identica is a 'creative insights business'; Circus says you'll find 'a unique mix of people in one, non-departmental, non-hierarchical company; Dragon is a 'hugely varied team'. And Faith Popcorn in the US has a BrainReserve Team who 'braille-read' culture to spot and hone trends.

This code indicates a new way of thinking about a) what needs to be done and b) how to go about doing it. A hugely varied team will come at a problem from many different startpoints. This is the practice of bricolage, using an eclectic mix of all possible ways of garnering information. And an outfit that is in the business of either creative insights or inventions will (must) find new and inventive ways of presenting their insights and inventions to clients. One has only to look at the high proportion of emotionally-charged visual material used by design and brand consultancy presentations compared with MR knowledge-based charts and reports.

If we think differently about what we are, we think differently about what we do. Which is where we came in.

\section{What can MR learn from this}

The emergent codes of strategic planning is moving in a different direction from the established MR discourse, a direction that appears to be closer to the world of $21^{\text {st }}$ century businesses and the worldview of our clients. If we ignore it, we will arguably reduce our sphere of influence to the narrow confines of the Research Department, which is, in and of itself, metamorphosing into the much less precise and more imaginative 'Consumer Insight Unit'. If we want to be at the top table, we have to look - and talk - like we belong there. However, this begs several questions, which must be addressed in the development of a new MR language model.

- These codes are not representative of all consultancies. They are the emergent, not the dominant system of their communications. Nonetheless they do make a pattern that indicates a new model of thinking is taking shape within this sector.

- MR agencies and companies are different from brand consultancies. We do have a central 'thing' that we do, our core product, without which we would not have either industry, profession or brand. We clearly cannot throw that baby out with the bathwater. However, in the findings of my analysis, we can no longer allow the tail of 'the traditional emphasis on research purity, de-personalised objectivity and detaching the facts from intuition or prior knowledge and experience $^{\text {xv }}$ to wag the whole MR dog.

- We are faced with a contradiction between the residual codes of 'research purity' and the emergent codes of 'feeling' and 'hanging loose'. Reconciling this contradiction is the final block in the new Language Model.

- A very new, emergent code is just peeping over the MR horizon, pointing the way towards resolving this contradiction and creating a new MR brand myth. This is the code of 'Imaginative Metonymy'. 


\section{New MR- the myth of 'Imaginative Metonymy'}

The myth is easier to see in a diagram.

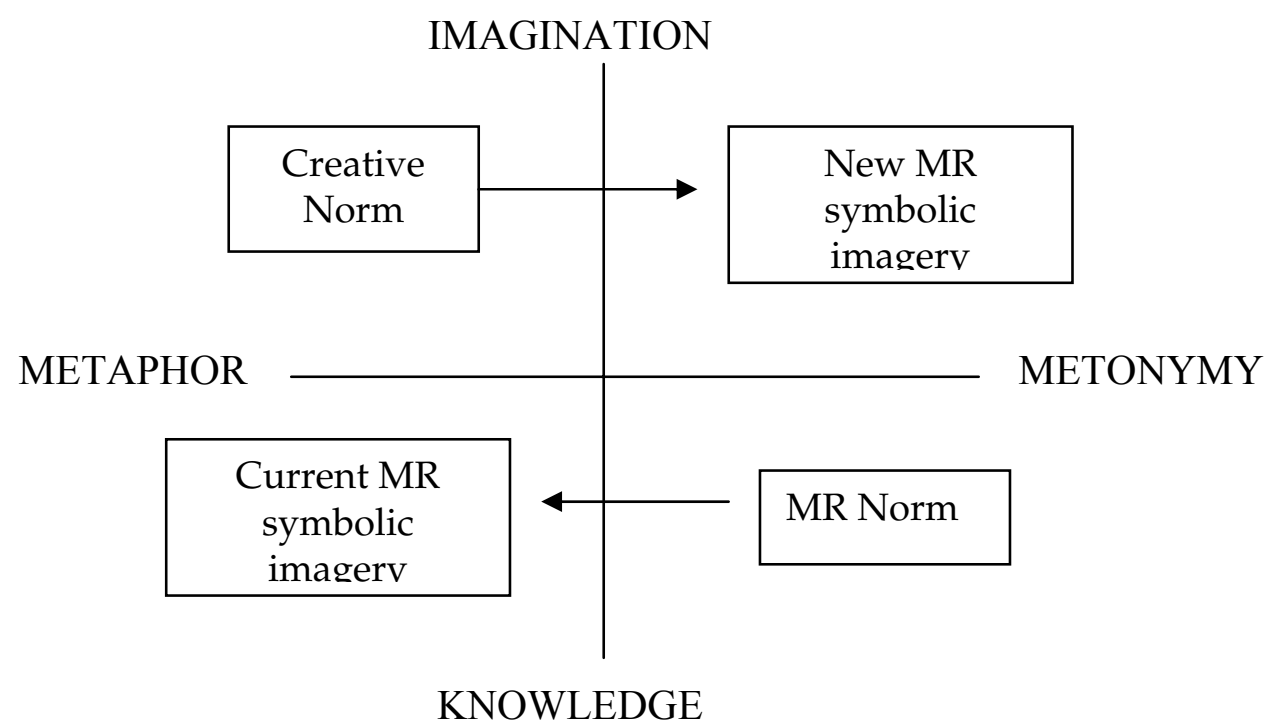

Currently MR is stuck in the bottom half of the quadrant, working to the codes of knowledge; either expressed metonymically, or through tired and cliché'd symbols and metaphors.

If however, we shift to the codes of imagination, which also encompass change, ambiguity, liminality, feelings and hanging loose, we have a new symbolic register, Imaginative Metonymy.

Imaginative Metonymy allows us to communicate new MR without losing everything that makes Research what it is. Metonymy grounds the imagination and creativity in the research product, while Imagination lifts research to new and inspired heights of interpretation and actionable insight.

Metonymy is the language of 'research'. Imaginative Metonymy is the language of 'insight'.

There is already some imaginative metonymy energing in the MR discourse.

We have mentioned above NOP's sharp use of precise ethnic imagery in its international advertising. The company also uses an image, which slips between metonymy and metaphor in its corporate ads, illustrating the headline 'A World of Difference' with a surreal and oddly beautiful spaceworld. For researchers (especially quallies) this also nudges us in the direction of The Brand Planet projective.

The Henley Centre's website starts with an intriguing use of metonymy in its wordcollage of contemporary life 


spider lives.blur.hedgedhedo
nism.homingfromwork.the con
tradictory consumer .homo lu
dens.time-juggling.media refl
ex.connoisseurship. perfectm
oments.attention evonomy. re
gendering. vice is nice. past as
playground. niagara of supply
pintglass of demand. ageless
ness. info-bartering. authentis
eeking. stress envy DeMAND

The point here is that, although the language is, broadly, metonymic, the genre - broken words, half-thoughts - acts as a metaphor for the way contemporary life is lived. This use of both axes of language thus projects an understanding of both the rational and the emotional side of the modern consumer's life.

Everyday Lives, the ethnographic agency pioneered by Siamack Salari is a pastmaster in creative metonymy. Their stand at Research Show featured a meticulously art-directed kitchen set, complete with cutout consumers, which stood out like a bright light in a naughty semiotic world of corporate exhibition design styles. And their tariff is printed like a supermarket checkout bill. However, as in the two examples above, the use of metonymy here is not disingenuous. The style of the art direction set up a knowing wink between addresser and addressee. This both created an emotional bond between the stand and the visitor and, very precisely, forced a space between the real lives that are the object of the ethnography - and the recreation of those lives in advertising and brand communications.

This semiotic tactic acts as a metaphor for an honest understanding of the role of research — and adds a truth and credibility to the company's offer.

And then there is the AQR logo where the $\mathrm{Q}$ is in the shape of a speech bubble. Metonymically this points of course to the reportage and use of consumer quotes, the hallmark of qualitative research debriefing. Metaphorically, however, it puts the voice of the consumer right at the heart of the concerns, thinking and philosophy of the AQR. Very different from the power game played by 'getting into the consumer's head'.

Using metonymy imaginatively propels it closer to metaphor, thereby giving MR language and communications an emotional dimension we do not have at the moment. But they key here is that it must be imaginative and must be seen to be so. Old unimaginative clichés will not do.

To return to Victor Turner's vision for the language of the liminal space.

In changing or newly established systems I would expect to find, in liminal situations, daring and innovation, both in the modes of relating symbolic and mythic elements and in the choice of elements to be related. There might also be the introduction of new elements and their various combination with old ones 
Following Turner, we need to find new modes for relating and reporting. New elements that can be combined with old elements in new ways. Arguably the case history of Van den Bergh's H\&A documentary videos, Seeing is Believing, presented at Conference last year fulfills exactly that imaginative metonymic criterion.

The aim of the videos, made in conjunction with What If TV, was not ethnographic observation but the dramatisation of a huge and fundamental piece of quantitative research

The purpose was not to replicate the research already conducted, but to bring to life what had just been learnt. It was to visualise a very difficult set of data, within a corporate culture that is visual, creative and qualitative.

It seems to me that this is increasingly the problem that we all face, and yet the MR discourse is still driven by residual codes of objective data. This begs the question, can the dominant oiltanker of MR's bread and butter measurement turn around as radically as this - or will the qualitative arm of the industry have to hive off and remake MR in its own image, getting closer to the creative brand consultancies as it goes? (An eminent MR Director told me that he believes client departments will split into Market Research Managers and Consumer Insight Managers).

From the analysis I might have answered yes to this last question and certainly I think that quallies are much more suited to the practice of bricolage and to offering 'possibilities' rather than 'answers' or 'facts' However the Van den Bergh experiment gives one hope. As Stephen Donaldson said

You still need to produce top quality consumer insight, based on robust techniques. But you need to broadcast the findings in a way that engages, informs and excites the audience in a way that drives the whole organisation to actually do something with the knowledge that you have spent so much time and money getting.

If we use our Research metonymy imaginatively enough we can do just that.

\footnotetext{
References

${ }^{\mathrm{i}}$ Barbara F Schaetti and Sheila J Ramsey, The Global Nomad Experience

ii The Death of Marketing: what now for Market Research, MRS Conference Research 2001

iii Wendy Gordon's seminal chart from Gordon/Valentine, The $21^{\text {st }}$ Century Consumer, MRS Conference 2000

iv See Ian Pearson, Cyberspace - from order to chaos and back

v Victor Turner, Dramas, Fields and Metaphors, Symbolic Action in Human Society

${ }^{v i}$ See Gordon and Valentine op cit

vii See sections on metaphor, Evans/Valentine, The Dark Side of The Onion MRS Conference, 1993

viii Quoted in Turner, op cit

ix Turner, quoted in Boundaries and Thresholds, ed Hilda Ellis Davidson

${ }^{x}$ Wendy Gordon and Sally Ford-Hutchinson, Brains and Brands - Rethinking The Consumer In The Light Of

Scientific Fact, to be published, Admap magazine, 2002

${ }^{x i}$ Quoted in Research December 2001
} 


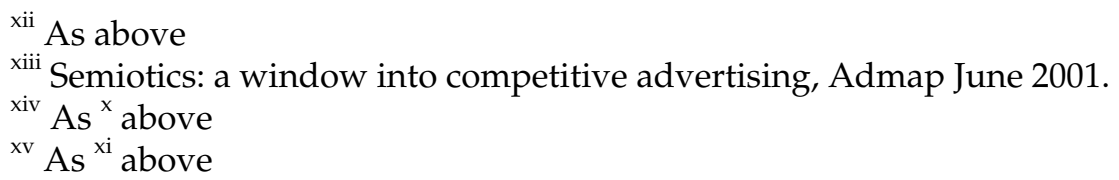

\section{Bibliography}

Davidson H. E. ed Boundaries and Thresholds, Gloucester, UK, 1993, Thimble Press

Dexter A and Smith D. Whenever I hear the word 'paradigm' I reach for my gun: how to stop talking and start walking, MRS Conference, Research 2001

Donaldson S. and Walter P. Seeing is Believing. Consumers do not live in reports and charts so why is consumer insight so often presented that way, MRS Conference, Research 2001

Evans M and Valentine V. The Dark Side of The Onion: rethinking the meanings of rational and emotional response, MRS Conference 1993

Earls M The Death of Marketing: what now for Market Research, MRS Conference, Research 2001

Floch J-M, Marketing and Communication : Beneath the Signs, the Strategies, Basingstoke, 2001, Palgrave

Gordon W and Valentine V The 21 ${ }^{\text {st }}$ Century Consumer, A new Model of Thinking, MRS Conference 2000

Gordon W. and Ford-Hutchinson S. Brains and Brands - Rethinking The Consumer In The Light Of Scientific Fact to be published, Admap magazine, 2002

Jakobson R and Halle M, Fundamentals of Language, Paris and The Hague, 1975, Mouton

Pearson I, Lyons, M and Greenop D. Cyberspace - from order to chaos and back, published in the BT Engineering Journal, Vol 1, Part 1, Jan-Mar 2000

Schaetti Barbara F and Ramsey Sheila J. The Global Nomad Experience, Living in Liminality, Originally published in Mobility, the monthly magazine of the Employment Relocation Council, September, 1999

Turner, V. Dramas, Fields and Metaphors, Symbolic Action In Human Society, USA, 1974, Cornell

\section{Acknowledgement}

I am very grateful to Adam Morgan of EatBigFish for generously allowing me to use his Challenger Brand development process in this paper 